\title{
Determination of Mercury(II) in Aquatic Plants Using Quinoline- Thiourea Conjugates as a Fluorescent Probe
}

\author{
Guodong Feng, Yuanyuan Ding, Zhiyong Gong, Yanna DAI, and Qiang FeI ${ }^{\dagger}$ \\ Department of Analytical Chemistry, College of Chemistry, Jilin University, Changchun 130021, P. R. China
}

\begin{abstract}
In this study, a quinoline-thiourea conjugate (1-phenyl-3-(quinoline-8-yl) thiourea, PQT) was synthesized and used as a fluorescence sensor to detect mercury ion. The observation is coincident with the well-documented phenomenon that a thiocarbonyl-containing group on a fluorochrome quenches the fluorescence due to the heavy atom effect of the $\mathrm{S}$ atom. The large fluorescence enhancement of PQT in the buffered MeCN-water mixture (1/1 v/v; HEPES $100 \mathrm{mM}$; $\mathrm{pH} 8.0)$ was caused by the $\mathrm{Hg}^{2+}$ induced transformation of the thiourea function into a urea group. As such, protic solvents can be ascribed to hydrogen bond formation on the carbonyl oxygen to reduce the internal conversion rate. The fluorescence intensity of PQT was enhanced quantitatively with an increase in the concentration of mercury ion. The limit of detection of $\mathrm{Hg}^{2+}$ was $7.5 \mathrm{nM}$. The coexistence of other metal ions with mercury had no obvious influence on the detection of mercury. A quinolone-thiourea conjugate was used as a fluorescent probe to detect $\mathrm{Hg}^{2+}$ in aquatic plants and the experimental results were satisfactory.
\end{abstract}

Keywords Fluorescent probe, PQT, mercury, aquatic plants

(Received April 6, 2013; Accepted May 16, 2013; Published July 10, 2013)

\section{Introduction}

Today, aquatic food is an important component of the human diet. Besides being a good source of minerals (phosphorus, iron, zinc, and potassium), vitamins (A, B6, and B12) and proteins, aquatic food products are low in saturated fat and rich in unsaturated fat. ${ }^{1}$ However, aquatic food contamination is frequently a subject of public debate and concern. This possible hazard is closely related to the fact that aquatic ecosystems act as the ultimate repository for all classes of contaminants. ${ }^{2}$ Mercury, a ubiquitous metal in water systems with both natural and anthropogenic sources, deserves special scrutiny due to its high toxicity. Mercury can be transferred from aquatic plants to aquatic food webs. ${ }^{3,4}$ Therefore, the determination of mercury in aquatic plants is very important.

Many techniques such as atomic absorption/emission spectroscopy, ${ }^{5-11}$ inductively coupled plasma mass spectrometry $(\mathrm{ICP}-\mathrm{MS})^{12}$ and electrochemical methods ${ }^{13,14}$ have been used to detect $\mathrm{Hg}^{2+}$ in environmental samples. Nevertheless, they require expensive and sophisticated instrumentation. ${ }^{15,16}$ In recent years, many efforts have been made to design various specialty chemosensors for $\mathrm{Hg}^{2+}$ ion detection. ${ }^{17-32}$ A very attractive approach focuses on the research of fluorescent $\mathrm{Hg}^{2+}$ ion sensors, ${ }^{33-40}$ which is highly effective for discriminating the presence of a target over the spectrally complex background inherent in real-world samples. Fluorescent probes for $\mathrm{Hg}^{2+}$ have been designed based on a reversible or irreversible fluorescence reaction. Although receptor-type probes are useful for reversible detection of $\mathrm{Hg}^{2+}$, dissociation constants $\left(K_{\mathrm{d}}\right)$

$\dagger$ To whom correspondence should be addressed.

E-mail: crdcai@jlu.edu.cn toward $\mathrm{Hg}^{2+}$ are determinant for their working concentration ranges, and this point is likely to limit their general and practical use. ${ }^{41}$ Thus, it is accepted that the detection of $\mathrm{Hg}^{2+}$ at $\mathrm{ppb}$ levels with high selectivity can be achieved by fluorescent probes based on irreversible fluorescence reactions rather than receptor-type probes. ${ }^{41-57}$ For the design of the irreversible fluorescent probes for $\mathrm{Hg}^{2+}$ detection, oxymercuration reaction has been recently explored. ${ }^{56,57}$ The design principle is quite interesting, but the technique requires high temperatures or long reaction times, especially for detecting $\mathrm{Hg}^{2+}$ at $\mathrm{ppb}$ levels. Although it is challenging to propose a totally new irreversible reaction such as oxymercuration, it seems difficult to find a more useful irreversible reaction than desulfurization, which has dominated as the most reliable irreversible reaction for the design of a fluorescent probe for $\mathrm{Hg}^{2+}$ detection. On the design principle by recourse of desulfurization, thiourea has played the most important role among thiocarbonyl containing groups. ${ }^{58-65}$

Herein, we have synthesized a quinolone-thiourea conjugate (1-phenyl-3-(quinoline-8-yl) thiourea, PQT) ${ }^{66,67}$ for desulfurization by $\mathrm{Hg}^{2+}$. The fluorescent probe has high sensitivity and selectivity for $\mathrm{Hg}^{2+}$ over other metal ions. We detected mercury in aquatic plants using the quinolone-thiourea conjugate as a fluorescent probe. In this study, an experimental approach based on incubation in indoor microcosms was tested to investigate the possible accumulation effect of the presence of mercury on aquatic plants in constructed freshwater ecosystems.

\section{Experimental}

Reagents and chemicals

Dichloromethane, acetonitrile and acetic ether were purchased from Tianjin Tiantai Fine Chemical Co., Ltd. (Tianjin, China). 


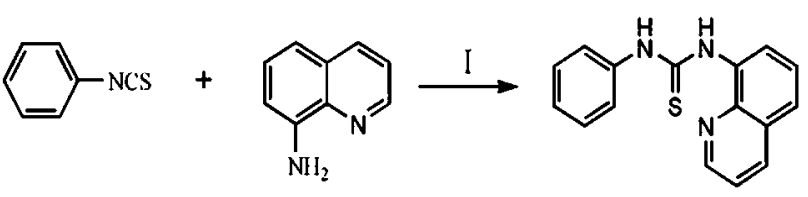

Scheme 1 Synthetic route of PQT. Reagents and conditions: (I) dried $\mathrm{CH}_{2} \mathrm{Cl}_{2}$, stirred for $48 \mathrm{~h}$.

A supply of 8-aminoquinoline was purchased from Matrix Scientific (Columbia, SC). Phenyl isothiocyanate was purchased from Acros Organics (Fair Lawn, NJ). $\mathrm{Hg}\left(\mathrm{NO}_{3}\right)_{2} \cdot 1 / 2 \mathrm{H}_{2} \mathrm{O}$ was purchased from Taixing Chemical Co., Ltd. (Nanjing, China). EDTA was purchased from Beijing Chemical Works (Beijing, China). HEPES was purchased from Beijing Dingguo Changsheng Biotechnology Co., Ltd. (Beijing, China). Twicedistilled water was used throughout all experiments. Thin layer chromatography (TLC) was carried out using silica gel 60 F254, and column chromatography was conducted over silica gel (300-400 mesh), both of which were obtained from the Qingdao Ocean Chemicals (Qingdao, China). All metal ion solutions were diluted from stock solutions.

Apparatus

The structures of compounds were identified by ${ }^{1} \mathrm{H}$ NMR and ${ }^{13} \mathrm{C}$ NMR (Varian Mercury 300 NMR spectrometer), using TMS as an internal standard. Chemical shifts $(\delta)$ are given in parts per million and coupling constants are given as absolute values expressed in hertz. High resolution mass spectra were measured with the Agilent 1290-micro TOF Q II mass spectrometer. Other mass spectra were measured with the Appied Biosystems api2000 Q-trap mass spectrometer. All fluorescence intensity and spectra were obtained using an RF-5301PC spectrofluorometer (Shimadzu, Japan) with excitation slit set at $5.0 \mathrm{~nm}$ and emission at $5.0 \mathrm{~nm}$. The $\mathrm{pH}$ measurements were carried out on a Sartorius PB-10 pH meter.

\section{Synthesis of $P Q T$}

A solution of phenyl isothiocyanate $(1.35 \mathrm{~g}, 10 \mathrm{mM})$ and 8-aminoquinoline $(1.29 \mathrm{~g}, 10 \mathrm{mM})$ in $\mathrm{CH}_{2} \mathrm{Cl}_{2}(30 \mathrm{~mL})$ was stirred at room temperature for $48 \mathrm{~h}$. The white crystals were precipitated in the solvent. The crystals were filtered out then washed with $\mathrm{CH}_{2} \mathrm{Cl}_{2}$. The reaction product was dried. The yield was 39\% (Scheme 1). HRMS (ESI+-TOF) $\mathrm{m} / z 280.0905$ $\left([\mathrm{M}+\mathrm{H}]^{+}\right.$calcd. for 280.0903$)$. ${ }^{1} \mathrm{H} N M R\left(\mathrm{CDCl}_{3}, 300 \mathrm{MHz}\right)$ $\delta 10.80(\mathrm{~s}, 1 \mathrm{H}), 9.46(\mathrm{dd}, J=9 \mathrm{~Hz}, J=1.8 \mathrm{~Hz}, 1 \mathrm{H}), 8.57(\mathrm{q}$, $J=4.2 \mathrm{~Hz}, J=1.8,1 \mathrm{H}), 8.14(\mathrm{~m}, 2 \mathrm{H}), 7.60-7.37(\mathrm{~m}, 8 \mathrm{H})$. ${ }^{13} \mathrm{C} \mathrm{NMR}\left(\mathrm{CDCl}_{3}, 75 \mathrm{MHz}\right) \delta(\mathrm{ppm}): 177.43,147.95,139.24$, 136.37, 134.79, 129.96, 127.87, 127.19, 126.81, 125.17, 122.24, 121.57, 117.34.

\section{Preparation of 1-phenyl-3-(quinolin-8-yl) urea (PQU)}

PQT $(0.128 \mathrm{~g}, 0.46 \mathrm{mM})$ and $\mathrm{Hg}\left(\mathrm{NO}_{3}\right)_{2} \cdot 1 / 2 \mathrm{H}_{2} \mathrm{O}(0.162 \mathrm{~g}$, $0.5 \mathrm{mM})$ in acetonitrile $(15 \mathrm{~mL})$ were stirred at room temperature for $60 \mathrm{~min}$. The red $\mathrm{HgS}$ was precipitated in the solution then the red precipitate was filtered out. The filtrate was concentrated in vacuo and then purified by flash column chromatography using dichloromethane and ethyl acetate $(2: 1, \mathrm{v} / \mathrm{v})$ as eluent to provide PQU as a white solid. ${ }^{1} \mathrm{H}$ NMR (DMSO, $300 \mathrm{MHz}$ ) $\delta 9.04(\mathrm{~S}, 1 \mathrm{H}), 7.95-7.97(\mathrm{~m}, 2 \mathrm{H}), 7.33-7.36(\mathrm{~m}, 3 \mathrm{H})$, $6.89-7.00(\mathrm{~m}, 3 \mathrm{H}), 6.83-6.85(\mathrm{dd}, 2 \mathrm{H}), 6.66-6.69(\mathrm{~m}, 1 \mathrm{H})$, $6.03-6.07$ (m, 1H); MS (ESI): $m / z, 262.1\left[\mathrm{M}-\mathrm{H}^{+}\right]$.

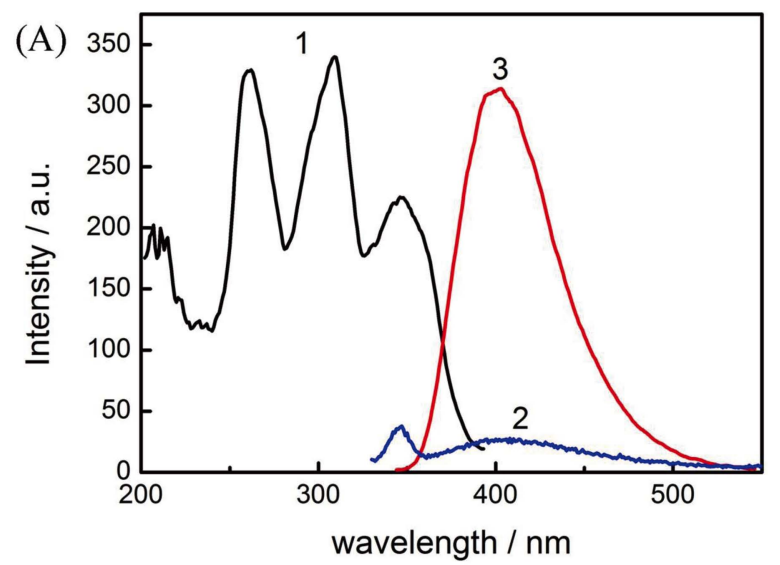

(B)
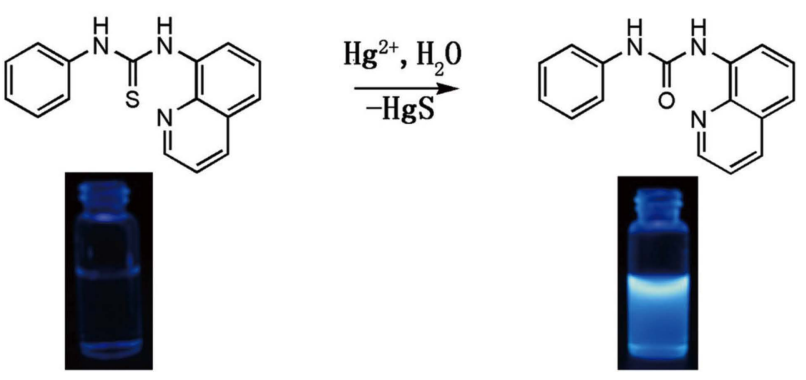

Fig. 1 (A) Excitation (1) and emission (2) spectra of PQT in a buffered MeCN-water mixture, emission (3) spectra of PQT solution with $\mathrm{Hg}^{2+}$. (B) The proposed mechanism for increasing fluorescence intensity of PQT upon $\mathrm{Hg}^{2+}$ addition, and fluorescence color change of the solution. Concentration of PQT, $10 \mu \mathrm{M} ; \mathrm{Hg}^{2+}, 10 \mu \mathrm{M} ; \lambda_{\mathrm{ex}}=$ $309 \mathrm{~nm} ; \lambda_{\mathrm{em}}=406 \mathrm{~nm}$.

\section{Digestion procedure of the aquatic plant}

The aquatic plants were triple-rinsed in deionized water, then oven-dried at $80^{\circ} \mathrm{C}$ to a constant weight. The sample was then reduced to a fineground. About $0.5 \mathrm{~g}$ of the sample was weighed into a dry, clean round-bottom flask. Next, $6 \mathrm{~mL}$ of $\mathrm{HCl}$ and $2 \mathrm{~mL}$ of $\mathrm{HNO}_{3}$ were added and the mixture was heated with a heating jacket. The temperature was gradually increased until heavy evolution of fumes ceased. If carbonization appeared, the vessel was removed from the hot plate, cooled and about $1 \mathrm{~mL}$ of $\mathrm{HNO}_{3}$ was added. The mixture was then heated again until complete digestion was achieved. The final residue was diluted to $10 \mathrm{~mL}$ with double deionized water.

\section{Results and Discussion}

\section{Fluorescence property of $P Q T$}

In a pH 8.0 HEPES buffer $(100 \mathrm{mM})$ containing $50 \% \mathrm{MeCN}$, fluorescence excitation and emission spectra of PQT were recorded and the results are shown in Fig. 1(A). The compound PQT exhibited weak fluorescence; the fluorescence emission peak was at $406 \mathrm{~nm}$ with an excitation wavelength of $309 \mathrm{~nm}$. This observation is coincident with the well-documented phenomenon that a thiocarbonyl-containing group on a fluorochrome quenches the fluorescence due to the heavy atom effect of the $\mathrm{S}$ atom. ${ }^{65-68}$ To our surprise, it was interesting to find that $\mathrm{Hg}^{2+}$ had an effect on the fluorescence emission of PQT. PQT also gave a shorter response time with $\mathrm{Hg}^{2+}$, and the enhanced response time ${ }^{69,70}$ was $2.5 \mathrm{~s}$. Within $2 \mathrm{~min}$, the 


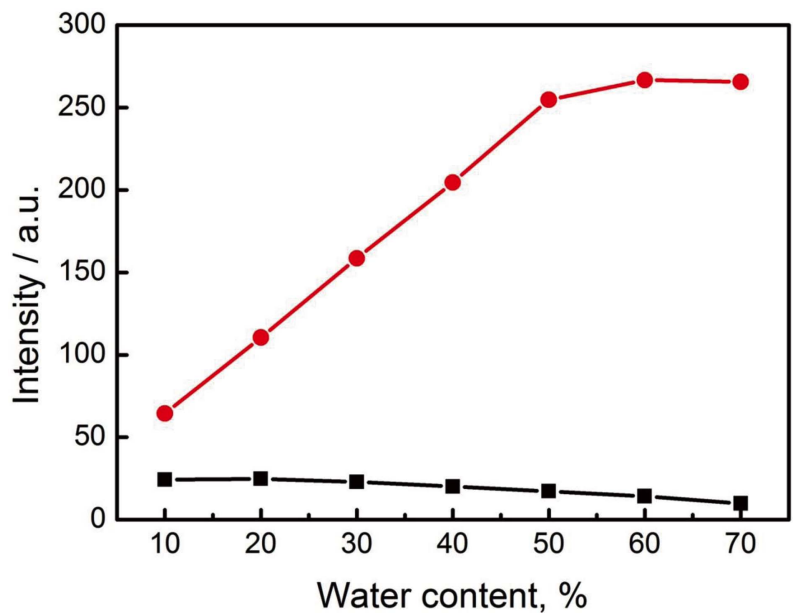

Fig. 2 Effect of water content on the fluorescence intensity of PQT measured without $(\mathbf{\square})$ and with $(\bullet) \mathrm{Hg}^{2+}$ in an aqueous $\mathrm{MeCN}$ solution (HEPES $100 \mu \mathrm{M})$. Concentration of PQT, $10 \mu \mathrm{M} ; \mathrm{Hg}^{2+}, 10 \mu \mathrm{M} ; \lambda_{\text {ex }}=$ $309 \mathrm{~nm} ; \lambda_{\mathrm{em}}=406 \mathrm{~nm}$.

fluorescence intensity of PQT after the addition of $\mathrm{Hg}^{2+}$ reached a constant value, which was about 10 times larger than the blank intensity (Fig. S9, Supporting Information). Mercury ion induced transformation of the thiourea function into a urea group of PQT is as depicted in Fig. 1(B). In the present case, the conversion was effective, occurring exclusively with $\mathrm{Hg}^{2+}$ ions in the HEPES buffer. The product of the reaction of PQT with $\mathrm{Hg}^{2+}$ was isolated, and identified as PQU.

\section{Effect of water content on the fluorescence response of $P Q T$}

The fluorescence measurements of PQU pure acetonitrile solution were taken every $10 \mathrm{~min}$ for $60 \mathrm{~min}$; there was no change in the fluorescence characteristics. However, an unexpectedly dramatic enhancement of PQU fluorescence emission was observed when 0.1 M HEPES $(\mathrm{pH}=8.0)$ was added to the solution of PQU in acetonitrile. A substantial red shift was also observed in the PQU fluorescence emission, from 357 to $406 \mathrm{~nm}$ (Fig. S10, Supporting Information). The remarkable fluorescence enhancement induced by protic solvents can be ascribed to hydrogen bond formation on the carbonyl oxygen of PQU; in polar protic solvents, the $S_{1}\left(\pi, \pi^{*}\right)$ state is subject to solvent stabilization, whereas the $S_{2}\left(n, \pi^{*}\right)$ state is destabilized by hydrogen bonding interactions with protic solvents, increasing the $S_{1}-S_{2}$ energy gap and thus reducing the internal conversion rate. ${ }^{71}$

In this part, the effects of water content on the fluorescence response of PQT to $\mathrm{Hg}^{2+}$ were investigated. Experimental results are shown in Fig. 2. The fluorescence (excited at $309 \mathrm{~nm}$ ) characteristic of PQT showed no obvious change in the water content range from 10 to $70 \%$. However, in the presence of the $\mathrm{Hg}^{2+}$ ion, there was a remarkable fluorescence enhancement of PQT under the water content from 10 to $50 \%$. From 50 to $70 \%$, the fluorescence change of PQT was unconspicuous. The white crystals were precipitated in the solvent when the water content was $80 \%$. Therefore, the water content of $50 \%$ was chosen as an optimum experimental condition.

Effect of $p H$ on the fluorescence response of $P Q T$

The effect of different $\mathrm{pH}$ levels of the PQT solution on sensing $\mathrm{Hg}^{2+}$ was also explored. As depicted in Fig. 3, the

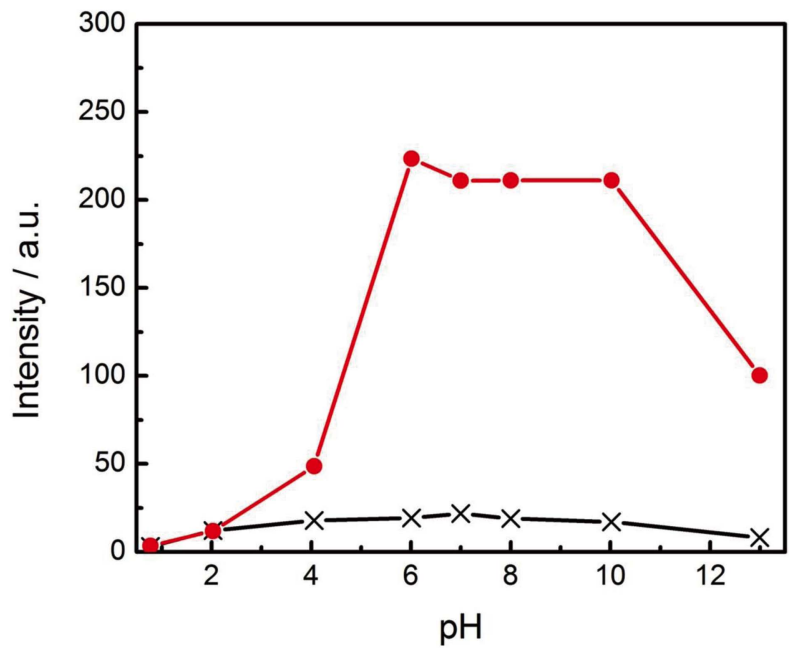

Fig. 3 Change in fluorescence intensity of PQT in a MeCN-water mixture measured with $(\bullet)$ and without $(\times) \mathrm{Hg}^{2+}$ as a function of $\mathrm{pH}$. Concentration of PQT, $10 \mu \mathrm{M} ; \mathrm{Hg}^{2+}, 10 \mu \mathrm{M} ; \lambda_{\mathrm{ex}}=309 \mathrm{~nm} ; \lambda_{\mathrm{em}}=$ $406 \mathrm{~nm} ; \mathrm{MeCN}$-water mixture (1/1 v/v).

fluorescence intensity (excited at $309 \mathrm{~nm}$ ) of PQT did not show significant change in the $\mathrm{pH}$ range from 1.0 to 13.0. However, in the presence of $\mathrm{Hg}^{2+}$, there was an obvious fluorescence off-on change of PQT with different fluorescence enhancement efficiency in the $\mathrm{pH}$ range from 2.0 to 6.0. The fluorescence intensity reached the maximum at $\mathrm{pH} 6.0$ and remained almost constant until pH 10.0, as shown in Fig. 3. Therefore, $\mathrm{pH} 8.0$ was chosen as the optimum experimental condition.

\section{Interference of large amount of common anions in $\mathrm{Hg}^{2+}$ determination}

An important feature of the sensor is its high selectivity toward mercury ions over other competitive species. The interference of a number of common anions for the detection of $\mathrm{Hg}^{2+}$ with PQT was carried out with excitation fixed at $309 \mathrm{~nm}$ and emission at $406 \mathrm{~nm}$. No significant fluorescence intensity changes were observed with common interference anions, such as $\mathrm{NO}_{3}^{-}, \mathrm{Cl}^{-}, \mathrm{CO}_{3}{ }^{2-}, \mathrm{F}^{-}, \mathrm{SO}_{4}{ }^{2-}, \mathrm{SCN}^{-}$and $\mathrm{Ac}^{-}$. In the competition experiments, the same concentration of the above-mentioned anions $(10 \mu \mathrm{M})$ were added to $10 \mu \mathrm{M}$ of $\mathrm{Hg}^{2+}$ in a buffered MeCN-water mixture (1/1 v/v; HEPES $100 \mathrm{mM}$; pH 8.0), and the fluorescence response of the chemosensor was detected and then compared with that of buffered $\mathrm{MeCN}$-water mixture (1/1 v/v; HEPES $100 \mathrm{mM}$; pH 8.0) containing only $10 \mu \mathrm{M}$ of $\mathrm{Hg}^{2+}$ (Fig. S11, Supporting Information). These experimental results showed that the response of the sensor to $\mathrm{Hg}^{2+}$ was unaffected by the presence of the other potentially contaminating anions.

\section{Selectively of $P Q T$ for $\mathrm{Hg}^{2+}$}

In addition, the interference of common metal ions for the detection of $\mathrm{Hg}^{2+}$ with PQT was carried out with excitation fixed at $309 \mathrm{~nm}$ and emission at $406 \mathrm{~nm}$. Figure 4 (the gray bar portion) illustrates the fluorescence response of PQT to different metal ions of interest; no significant fluorescence intensity changes were observed with common interferences such as alkali, alkaline earth, and transitional metal ions, indicating that other metal ions did not induce transformation of the thiourea function of PQT into a urea group and our proposed sensor exhibits high selectivity to $\mathrm{Hg}^{2+}$ over other metal ions. To test 


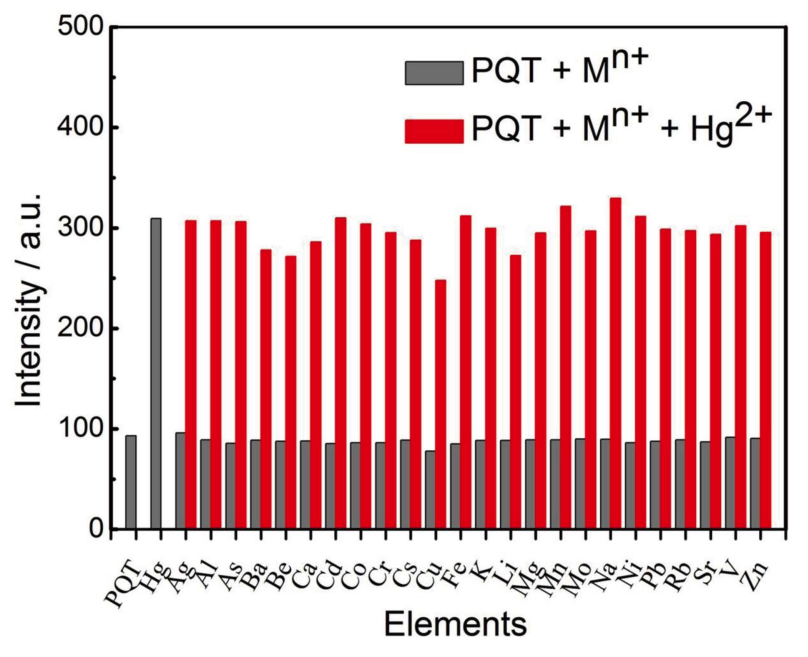

Fig. 4 Fluorescence response of PQT in a buffered $\mathrm{MeCN}$-water mixture to $10 \mu \mathrm{M}$ of $\mathrm{Hg}^{2+}$ or $10 \mu \mathrm{M}$ of other metal ions (the gray bar portion) and to the mixture of $10 \mu \mathrm{M}$ of other metal ions with $10 \mu \mathrm{M}$ of $\mathrm{Hg}^{2+}$ (the red bar portion). Concentration of PQT, $30 \mu \mathrm{M}$; buffered $\mathrm{MeCN}$-water mixture (1/1 v/v; HEPES $100 \mathrm{mM}$; $\mathrm{pH} 8.0)$.

practical applicability of our fluorescence chemosensor for $\mathrm{Hg}^{2+}$, competition experiments were also carried out. The same concentration of the above-mentioned metal ions $(10 \mu \mathrm{M})$ were added to $10 \mu \mathrm{M}$ of $\mathrm{Hg}^{2+}$ in a buffered $\mathrm{MeCN}$-water mixture $(1 / 1 \mathrm{v} / \mathrm{v}$; HEPES $100 \mathrm{mM}$; $\mathrm{pH} 8.0)$, and the fluorescence response of the chemosensor was detected and then compared with that of buffered MeCN-water mixture $(1 / 1 \mathrm{v} / \mathrm{v}$; HEPES $100 \mathrm{mM}$; pH 8.0) containing only $10 \mu \mathrm{M}$ of $\mathrm{Hg}^{2+}$. The results are also shown in Fig. 4 (the red bar portion). Figure 4 shows that $\mathrm{Ba}^{2+}, \mathrm{Be}^{2+}, \mathrm{Ca}^{2+}$ and $\mathrm{Li}^{+}$have a fluorescence quenching effect of $10 \%$ and $\mathrm{Cu}^{2+}$ has an interference quenching effect of $20 \%$. The indicates that these metal ions form a complex with PQT. When the fluorescence response of PQT for $\mathrm{Hg}^{2+}$ was detected with these coexisting ions, these ions would consume a certain concentration of PQT. So, the fluorescence response of PQT to $\mathrm{Hg}^{2+}$ with these coexisting ions is lower than PQT containing only $\mathrm{Hg}^{2+}$. In this part, EDTA was chosen as a masking agent to eliminate the interference of these ions. The effect of EDTA content on the fluorescence response of PQT to $\mathrm{Hg}^{2+}$ was investigated. The fluorescence characteristic of PQT showed no obvious change with the addition of EDTA content ranging from 1 to 30 equiv. of $\mathrm{Hg}^{2+}$. The fluorescence quenching effect of PQT to $\mathrm{Hg}^{2+}$ was less than $15 \%$ with EDTA content range from 40 to 100 equiv. (Fig. S13, Supporting Information). EDTA as a masking agent was examined for $\mathrm{Ba}^{2+}, \mathrm{Be}^{2+}, \mathrm{Ca}^{2+}$, $\mathrm{Cu}^{2+}$ and $\mathrm{Li}^{+}$at concentrations not affecting the determination of $\mathrm{Hg}^{2+}$. A 10 -fold excess of $\mathrm{Cu}^{2+}$ could be masked with EDTA and equal amounts of $\mathrm{Ba}^{2+}, \mathrm{Be}^{2+}, \mathrm{Ca}^{2+}$ and $\mathrm{Li}^{+}$could be eliminated with EDTA (Fig. S14, Supporting Information).

These experimental results showed that the response of the sensor to $\mathrm{Hg}^{2+}$ was unaffected by the presence of the other potentially contaminating metal ions. These results implied that the selectivity of PQT toward $\mathrm{Hg}^{2+}$ was remarkable, suggesting PQT is a viable selective chromogenic sensor for $\mathrm{Hg}^{2+}$.

Fluorescence response of $P Q T$ to $\mathrm{Hg}^{2+}$

Under conditions of $\mathrm{pH} 8.0$ HEPES buffer $(100 \mathrm{mM})$ containing 50\% MECN and with the excitation and emission slits set to a 5-nm band-pass, we observed that the fluorescence response of PQT increased upon increasing the $\mathrm{Hg}^{2+}$
Table 1 Results of the sample analysis and recovery of added $\mathrm{Hg}^{2+}$ in aquatic plants

\begin{tabular}{ccccc}
\hline Sample & $\begin{array}{c}\text { Found/ } \\
\mu \mathrm{mol}\end{array}$ & $\begin{array}{c}\mathrm{Hg} \text { added } / \mathrm{mol} \\
\mu \mathrm{mol}\end{array}$ & $\begin{array}{c}\mathrm{Hg} \text { found } / \\
\mu \mathrm{mol}\end{array}$ & $\begin{array}{c}\text { Recovery, } \\
\%\end{array}$ \\
\hline $\begin{array}{c}\text { Microsorium } \\
\text { pteropus }\end{array}$ & 3.68 & 1.00 & 1.01 & 101 \\
Anubias nana & 3.11 & 2.00 & 1.99 & 99.5 \\
& & 2.00 & 0.98 & 98 \\
Bacopa & 3.07 & 1.00 & 2.04 & 102 \\
caroliniana & & 2.00 & 0.97 & 97 \\
Echinodorus & 5.16 & 1.00 & 0.97 & 98 \\
uruguayensis & & 2.00 & 2.07 & 103.5 \\
\hline
\end{tabular}

a. Amount of $\mathrm{Hg}^{2+}$ added to each sample.

b. Amount of $\mathrm{Hg}^{2+}$ detected in each sample.

concentration over the range of $1-40 \mu \mathrm{M}$ (Fig. S15A, Supporting Information). As shown in the inset of Fig. S15A, we found that the fluorescence intensity of PQT increased with an increase of the concentration of $\mathrm{Hg}^{2+}$ from 1 to $10 \mu \mathrm{M}$. When the concentration of $\mathrm{Hg}^{2+}$ exceeded $10 \mu \mathrm{M}$, the fluorescence intensity of PQT showed no apparent change. After the slits were set to $10 \mathrm{~nm}$ for both excitation and emission, the fluorescence spectra of PQT with $\mathrm{Hg}^{2+}$ concentration from 0 to $900 \mathrm{nM}$ was measured (Fig. S15B, Supporting Information). The inset of Fig. S15B shows the line curve of fluorescence intensity of PQT titrated with $\mathrm{Hg}^{2+}$ concentration. The limit of detection of PQT to $\mathrm{Hg}^{2+}$ was $7.5 \mathrm{nM}$. Thus, our present approach provides a highly sensitive fluorescence probe for detecting $\mathrm{Hg}^{2+}$ in the water or biological samples.

\section{Detection of $\mathrm{Hg}^{2+}$ in aquatic plants}

The practical application of the designed chemosensor was evaluated by using it to detect $\mathrm{Hg}^{2+}$ in four kinds of aquatic plants. Aquatic plants were put in a glass culture cylinder measuring in $16 \mathrm{~cm}$ of diameter with $4 \mathrm{~L}$ of deionized water with $800 \mu \mathrm{M} \mathrm{Hg}^{2+}$. After a week, the aquatic plants were rinsed in deionized water, and dried at $80^{\circ} \mathrm{C}$ to a constant weight. The samples $(0.5 \mathrm{~g})$ were wet digested and diluted to $10 \mathrm{~mL}$ with double deionized water. In order to reduce the $\mathrm{pH}$ influence in the detection, $4 \mathrm{~mL}$ of HEPES buffered water/MeCN containing PQT was added to $1 \mathrm{~mL}$ of the sample to keep the $\mathrm{pH}$ value at 8.0 , and then its fluorescence intensity change was measured. The $\mathrm{Hg}$ concentrations of the samples were determined by the optimized fluorometric procedure, and the results obtained are summarized in Table 1. The concentrations of $\mathrm{Hg}^{2+}$ in Bacopa caroliniana was the lowest. Therefore, we surmise aquatic plants with large leaves like Echinodorus uruguayensis have greater ability to accumulate the $\mathrm{Hg}^{2+}$ in freshwater ecosystems. Recovery experiments for varying added amounts of $\mathrm{Hg}^{2+}$ were carried out, and the experimental results are also shown in Table 1. These results confirmed the validity of the proposed method.

\section{Conclusions}

In conclusion, we have demonstrated that PQT as a fluorescent probe for the detection of $\mathrm{Hg}^{2+}$ shows high sensitivity and the fluorescence intensity increases quantitatively with an increase in the $\mathrm{Hg}^{2+}$, with a limit of detection of $7.5 \mathrm{nM}$. PQT has higher selectivity for $\mathrm{Hg}^{2+}$ than other metal ions. When the other metal 
ions coexist with $\mathrm{Hg}$, there is no obvious influence on the detection of mercury. The lowest test concentration of $\mathrm{Hg}^{2+}$ in this assay was $20 \mathrm{nM}(0.004 \mathrm{mg} / \mathrm{L})$. This study suggests that the determination of mercury in aquatic plants using the quinolone-thiourea conjugate as a fluorescent probe is viable.

\section{Acknowledgements}

The authors are grateful for the financial support from the Basic Research Foundation of Jilin University (Nos. 201103096 and 201103102) and the Science-Technology Development Project of Jilin Province of China (No. 201105008).

\section{Supporting Information}

Characterization Data of obtained compounds, fluorometric analysis and supplementary figures. This material is available free of charge on the Web at http://www.jsac.or.jp/analsci/.

\section{References}

1. J. Lloret, Mar. Pollut. Bull., 2010, 60, 1640.

2. I. Ahmad, J. P. Coelho, I. Mohmood, N. A. Anjum, M. Pacheco, M. A. Santos, A. C. Duarte, and E. Pereira, Food Chem., 2012, 133, 665.

3. R. Correia, D. Oliveira, and J. Guimarães, Aquat. Geochem., 2012, $18,421$.

4. N. Regier, F. Larras, A. G. Bravo, V. G. Ungureanu, D. Amouroux, and C. Cosio, Chemosphere, 2013, 90, 595.

5. D. Karunasagar, J. Arunachalam, and S. Gangadharan, $J$. Anal. At. Spectrom., 1998, 13, 679.

6. Y. Yamini, N. Alizadeha, and M. Shamsipur, Anal. Chim. Acta, 1997, 355, 69.

7. E. Kopysc, K. Pyrzynska, S. Garbos, and E. Bulska, Anal. Sci., 2000, 16, 1309.

8. T. Duan, X. Song, J. Xu, P. Guo, H. Chen, and H. Li, Spectrochim. Acta, Part B, 2006, 61, 1069.

9. J. V. Cizdziel and S. Gerstenberger, Talanta, 2004, 64, 918.

10. Z. L. Zhu, G. C. Y. Chan, S. J. Ray, X. R. Zhang, and G. M. Hieftje, Anal. Chem., 2008, 80, 7043.

11. Z. L. Zhu, G. C. Y. Chan, S. J. Ray, X. R. Zhang, and G. M. Hieftje, Anal. Chem., 2008, 80, 8622.

12. L. Jian, W. Goessler, and K. J. Irgolic, Fresenius J. Anal. Chem., 2000, 366, 48.

13. X. C. Fu, X. Chen, Z. Guo, L. T. Kong, J. Wang, J. H. Liu, and X. J. Huang, Electrochim. Acta, 2010, 56, 463.

14. T. Alizadeh, M. R. Ganjali, and M. Zare, Anal. Chim. Acta, 2011, 689, 52.

15. S. Young, Spectrochim. Acta, Part A, 2007, 68, 705.

16. Y. Long, D. Jiang, X. Zhu, J. Wang, and F. Zhou, Anal. Chem., 2009, 81, 2652.

17. A. Coskun, M. D. Yilmaz, and E. U. Akkaya, Org. Lett., 2007, 9, 607.

18. M. H. Lee, J. S. Wu, J. W. Lee, J. H. Jung, and J. S. Kim, Org. Lett., 2007, 9, 2501.

19. J. Wang and X. Qian, Org. Lett., 2006, 8, 3721.

20. S. Yoon, A. E. Albers, A. Wong, and C. J. Chang, J. Am. Chem. Soc., 2005, 127, 16030.

21. X. Guo, X. Qian, and L. Jia, J. Am. Chem. Soc., 2004, 126, 2272.

22. E. M. Nolan and S. J. Lippard, J. Am. Chem. Soc., 2003, $125,14270$.
23. X. Zhu, S. Fu, W. Wong, J. Guo, and W. Wong, Angew. Chem., Int. Ed., 2006, 45, 3150.

24. E. M. Nolan and S. Lippard, J. Chem. Rev., 2008, 108, 3443.

25. J. Manimala and E. V. Anslyn, Eur. J. Org. Chem., 2002, 3909.

26. K. S. Kim and L. Qian, Tetrahedron Lett., 1993, 34, 7677.

27. R. A. Batey and D. A. Powell, Org. Lett., 2000, 2, 3237.

28. D. Boeglin, S. Cantel, A. Heitz, J. Martinez, and J. A. Fehrentz, Org. Lett., 2003, 5, 4465.

29. M. Y. Chae and A. W. Czarnik, J. Am. Chem. Soc., 1992, $114,9704$.

30. G. Hennrich, W. Walther, U. Resch-Genger, and H. Sonnenschein, Inorg. Chem., 2001, 40, 641.

31. K. C. Song, J. S. Kim, S. M. Park, K. C. Chung, S. Ahn, and S. K. Chang, Org. Lett., 2006, 8, 3413.

32. S. K. Ko, Y. K. Yang, J. Tae, and I. Shin, J. Am. Chem. Soc., 2006, 128, 14150 .

33. H. Zheng, X. J. Zhang, X. Cai, Q. N. Bian, M. Yan, G. H. Wu, X. W. Lai, and Y. B. Jiang, Org. Lett., 2012, 14, 1986.

34. L. H. Wu, L. F. Han, Y. B. Ruan, and Y. B. Jiang, Chin. J. Anal. Chem., 2010, 38, 121.

35. X. Q. Liu, X. Shu, X. Zhou, X. Zhang, and J. Zhu, J. Phys. Chem. A, 2010, 114, 13370.

36. M. G. Choi, D. H. Ryu, H. L. Jeon, S. Cha, J. Cho, H. H. Joo, K. S. Hong, C. Lee, S. Ahn, and S. K. Chang, Org. Lett., 2008, 10, 3717.

37. K. N. Kim, M. G. Choi, J. H. Noh, S. Ahn, and S. K. Chang, Bull. Korean Chem. Soc., 2008, 29, 571.

38. Y. Xia and C. Zhu, Talanta, 2008, 75, 215.

39. S. Y. Moon, N. J. Youn, S. M. Park, and S. K. Chang, J. Org. Chem., 2005, 70, 2394.

40. R. Martinez, A. Espinosa, A. Tarraga, and P. Molina, Org. Lett., 2005, 7, 5869 .

41. E. M. Nolan and S. J. Lippard, Chem. Rev., 2008, 108, 3443.

42. H. Zheng, Z. H. Qian, L. Xu, F. F. Yuan, L. D. Lan, and J. G. Xu, Org. Lett., 2006, 8, 859 .

43. S. Voutsadaki, G. K. Tsikalas, E. Klontzas, G. E. Froudakis, and H. E. Katerinopoulos, Chem. Commun., 2010, 46, 3292.

44. Z. Q. Hu, C. S. Lin, X. M. Wang, L. Ding, C. L. Cui, S. F. Liu, and H. Y. Lu, Chem. Commun., 2010, 46, 3765.

45. W. Lin, X. Cao, Y. Ding, L. Yuan, and Q. Yu, Org. Biomol. Chem., 2010, 8, 3618 .

46. Y. Zhou, X. Y. You, Y. Fang, J. Y. Li, K. Liu, and C. Yao, Org. Biomol. Chem., 2010, 8, 4819.

47. G. Zhang, D. Zhang, S. Yin, X. Yang, Z. Shuai, and D. Zhu, Chem. Commun., 2005, 2161.

48. B. Liu and H. Tian, Chem. Commun., 2005, 3156.

49. Y. K. Yang, K. J. Yook, and J. Tae, J. Am. Chem. Soc., 2005, $127,16760$.

50. X. Zhang, Y. Xiao, and X. Qian, Angew. Chem., Int. Ed., 2008, 47, 8025.

51. W. Shi and H. Ma, Chem. Commun., 2008, 1856.

52. M. G. Choi, Y. H. Kim, J. E. Namgoong, and S. K. Chang, Chem. Commun., 2009, 3560.

53. W. Jiang and W. Wang, Chem. Commun., 2009, 3913.

54. M. H. Lee, S. W. Lee, S. H. Kim, C. Kang, and J. S. Kim, Org. Lett., 2009, 11, 2101.

55. F. Song, S. Watanabe, P. E. Floreancig, and K. Koide, $J$. Am. Chem. Soc., 2008, 130, 16460.

56. M. Santra, D. Ryu, A. Chatterjee, S. K. Ko, I. Shin, and K. H. Ahn, Chem. Commun., 2009, 2115.

57. Y. S. Cho and K. H. Ahn, Tetrahedron Lett., 2010, 51, 
3852.

58. P. Z. Qin, C. G. Niu, G. M. Zeng, J. H. Zhu, and L. Yue, Anal. Sci., 2008, 24, 1205.

59. L. Zhou, Y. Wang, Z. Liu, and Q. Huang, J. Hazard. Mater., 2009, 161, 995.

60. Y. Shiraishi, S. Sumiya, and T. Hirai, Org. Biomol. Chem., 2010, 8, 1310.

61. K. Tsukamoto, Y. Shinohara, S. Iwasaki, and H. Maeda, Chem. Commun., 2011, 47, 5073.

62. S. Sumiya, T. Sugii, Y. Shiraishi, and T. Hirai, J. Photochem. Photobiol., A, 2011, 219, 154.

63. H. Li and H. Yan, J. Phys. Chem. C, 2009, 113, 7526.

64. C. Y. Wu, C. C. Lin, T. M. Fu, C. R. Yang, and Y. P. Yen, J. Chem., 2010, 63, 329.

65. W. C. Lin, C. Y. Wu, Z. H. Liu, C. Y. Lin, and Y. P. Yen,
Talanta, 2010, 81, 1209.

66. H. Poradowska, K. Nowak, and W. Czuba, Pol. J. Chem., 1979, 53, 1895.

67. D. M. Wiles and T. Suprunchuk, J. Chem. Eng. Data, 1969, 14, 506 .

68. N. J. Turro, V. Ramamurthy, and J. C. Scaiano, "Principles of Molecular Photochemistry: An Introduction", 2009, University Science Books, California, 311.

69. X. L. Liu, X. F. Zhang, R. Lu, P. C. Xue, D. F. Xu, and H. P. Zhou, J. Mater. Chem., 2011, 21, 8756.

70. P. C. Xue, R. Lu, J. H. Jia, M. Takafuji, and H. Ihara, Chem. Eur. J., 2012, 18, 3549.

71. A. Kobayashi, K. Takehira, T. Yoshihara, S. Uchiyama, and S. Tobita, Photochem. Photobiol. Sci., 2012, 11, 1368. 